\title{
Acceptance and Commitment Therapy for "Taro," a Japanese Client with Chronic Depression: A Replicated Treatment-Evaluation
}

\section{TAKASHI MUTO ${ }^{\mathrm{a}, \mathrm{c}}$ \& TAKASHI MITAMURA ${ }^{\mathrm{b}}$}

\author{
${ }^{\text {a }}$ Department of Psychology, Doshisha University, Kyoto, Japan \\ $\mathrm{b}$ Department of Social Work, Kansai University of Welfare Sciences, Osaka, Japan \\ ${ }^{\mathrm{c}}$ Correspondence regarding this article should be addressed to Takashi Muto, Department of Psychology, Doshisha \\ University, Tatara Miyakotani 1-3, Kyotanabe-shi, Kyoto, Japan, 610-0394 \\ Email: takamuto@mail.doshisha.ac.jp
}

\begin{abstract}
This single case study examined the effectiveness of Acceptance and Commitment Therapy (ACT) for "Taro," a chronically depressed Japanese man in his thirties. After his baseline functioning was recorded, 9 one-hour weekly sessions, 3 biweekly one-hour booster sessions (bibliotherapy using ACT self-help reading materials), and then 4 monthly follow-up sessions, were conducted. The study examines the outcome of each of the treatment components, which were introduced in a step-by-step manner. In addition, the effects of interventions directed at each core process were also tested. As a result, the effectiveness of ACT was demonstrated with a chronically depressed Japanese client. The effectiveness of interventions was remarkably high during weekly therapy until the booster sessions; in the follow-up stage previous gains were first maintained, but then showed some regression as the client's job situation deteriorated. Future directions include the identification of factors that maintain an increase in the effectiveness of ACT interventions.
\end{abstract}

Key words: Acceptance and Commitment Therapy; chronic depression; Japanese client; treatment evaluation; case study clinical case study

\section{CASE CONTEXT AND METHOD}

\section{(a) Purpose of this Study and Rationale for Selecting the Client}

Japanese clinical psychology has tended to dichotomize clinical approaches as either "spiritual" (albeit pantheistic) or "scientific," which detracts from their accountability and capacity to profit from the virtues of science. The design of the present case study is offered as an illustration of how clinical therapy cases can systematically combine complex qualitative clinical detail and clinical theory with standardized quantitative methods and statistics, and not rule out a spiritual perspective where helpful. And in fact the theoretical model and procedures employed involve mindfulness and openness to experience that are consistent with some of the Buddhist religious ideas and practices that have been part of Japan's "spiritual' tradition. 
Acceptance and Commitment Therapy for "Taro," a Japanese Client

Up to this point, there have been only two case study articles on ACT as applied to Japanese clients published in Japanese-language academic journals. The first one was by Masuda, Muto, Hayes \& Lillis (2008), although the therapy itself was conducted in the U.S. The other was by Muto (2012). Both of these studies employed treatment-evaluation with a time-series design, i.e., measuring changes in process and outcome over the course of different phases of therapy.

The case study by Muto (2012) examined a therapy case conducted in Japan with a 48 year-old male client who, over an approximate 10-year period, repeatedly took leaves of absence from work due to chronic depression. Twelve sessions of therapy including assessment were carried out. By session 10, the client had improved significantly according to the process scale of ACT, the Acceptance and Action Questionnaire-Second Edition (AAQ-II; Kishita, Yamamoto \& Shimada, 2008), and his improvement was maintained thereafter. In addition, his depression as measured by the Beck Depression Inventory-Second Edition (BDI-II; Kojima \& Furukawa, 2003) went below the cutoff point at session 9 and was stabilized. As an outcome measure for actual behavior activation, both a checklist for frequency of engagement in new activities and a pedometer were used. The frequency of new activities increased only while treatment was provided. On the other hand, the pedometer recorded no improvement as a result of ACT intervention (however, it's important to note that at the introduction of ACT treatment, the client's daily steps were already at the average for a Japanese man of his age). In the follow-up period, scores on the AAQ-II remained at the same level as that of the intervention period, and scores on the BDI-II improved over those of the treatment period. Five months after having returned to work, the client had not missed work for any reason other than physical illness. The case study thus demonstrated clinically significant change and its process was described in a time series manner.

However, in terms of its scientific validity, Muto (2012) left room for the following improvements: (a) providing an objective measurement of the client's stable baseline condition before intervention is introduced; (b) providing sufficient information concerning the clinical setting, therapist, and the cost of therapy; (c) providing data to evaluate social validity, including client satisfaction; (d) providing data on treatment integrity and adherence.

The aim of this present study, therefore, is to examine the process and outcome of a single case closely resembling that of Muto (2012) in that it also involves a client with several years' history of absenteeism due to chronic depression, in order to replicate the findings in a more scientifically rigorous manner.

\section{(b) The Clinical Setting in which Treatment Took Place}

\section{Clinical Setting and Institute}

Therapy was conducted in a training and research clinic hosted by the psychology department of a university. The clinic serves the local community and is used to train graduate students in clinical psychology. The university is centrally located in the city and is easily accessible. It is open Monday through Friday from 11 a.m. to 7 p.m. The clinic is staffed by five 
Acceptance and Commitment Therapy for "Taro," a Japanese Client

supervisory graduate school faculty members, two in-house psychologists, and one administrator. The faculty members are mandated to work one or two days in the clinic conducting therapy and supervising trainees (they are not, however, paid additionally for these services). Students of the university are excluded as clientele of the clinic. The cost of therapy is 3500 yen, which is equivalent to about $\$ 35$, for the initial intake session and 2500 yen for each subsequent session. Fees are not covered by national or other public health insurance programs.

\section{Physical Setting}

Therapy was conducted in a room measuring $2.4 \mathrm{~m}(\mathrm{H}) \times 3.0 \mathrm{~m}(\mathrm{~W}) \times 4.0 \mathrm{~m}(\mathrm{D})$.

The client sat at a 90-degree angle across the table $(0.7 \times 1.8 \times 0.9 \mathrm{~m})$ from the therapist. The session duration was 90 minutes, including time for filling out pre- or post-session questionnaires. Sessions were recorded on a digital audio recorder except for two occasions when the recorder did not work properly due to a mechanical problem.

\section{Frequency of Sessions}

The intake session and subsequent treatment sessions were conducted weekly. The follow up sessions after the client had returned to regular work were conducted every 3 to 4 weeks. There was a two-week period during the winter holidays when sessions were not conducted. One meeting was cancelled when the client's child was sick.

\section{(c) Method: Treatment Evaluation with Time Series Design}

This case study was designed as a treatment evaluation rather than a treatment research. In chapter 10 of The Scientist Practitioner: Research and accountability in the age of managed care $\left(2^{\text {nd }}\right.$ Ed.), Hayes, Barlow and Nelson-Gray (1999) described the differing features between treatment evaluation and treatment research. According to these authors, the two are identical in gathering data systematically, specifying intervention, evaluating the outcome of intervention, and reporting the findings. On the other hand, they are different in terms of the selection of clients, methods for setting research questions, and methods for selecting research design. In treatment studies, scientific criteria associated with laboratory-like control are used to make decisions on these three matters. On the other hand, treatment evaluation studies are designed and executed according to therapeutic criteria, giving priority to the resolution of client problems and the satisfaction of client needs over identifying control variables in detail.

More specifically, the following 7 questions are posed in order to evaluate the treatment evaluation design: (1) How did the client come to be in treatment? (Answer: By routine clinical channels); (2) Why is the client being kept in therapy? (Answer: To meet the client's needs); (3) Why was the target behavior selected? (Answer: to meet the client's needs); (4) Why are these measures being taken? (Answer: To assess client progress); (5) Why is intervention being timed this way? (Answer, To meet the client's needs); (6) Why is this intervention being used? (Answer: To help the client and/or to clarify client's needs); and (7) Why are control conditions used? (Answer: To help understand the client's needs). 
Acceptance and Commitment Therapy for "Taro," a Japanese Client

The design of the study followed an A/B/A' withdrawal design, with $\mathrm{A}$ as the baseline condition and $\mathrm{B}$ as the ACT intervention. The second $\mathrm{A}^{\prime}$ was unplanned and occurred as a result of the client's return to work, which prevented him from continuing sessions.

\section{(d) Therapist}

The first author served as the therapist. He is a university professor in his forties who teaches clinical psychology at both the undergraduate and graduate (including doctoral) levels. He works as a supervisor and as a therapist at the clinic where this therapy was conducted once or twice a week. His clinical orientation is based on clinical behavior analysis, and his postgraduate clinical and research experience spans about 15 years. Three years prior to conducting this case, the therapist studied as a visiting research professor at the University of Nevada, Reno for one year, with Steven C. Hayes, one of the founders of ACT. After returning to Japan he has translated the intervention manual and ACT self-help books, averaging two books a year. He has also led ACT workshops for Japanese clinicians five times yearly since his return.

\section{(e) Procedure}

In the Baseline Sessions 1 through 3, information about presenting problems was gathered, and the M.I.N.I. 5.0.0 (The Mini-International Neuropsychiatric Interview; Sheehan \& Lecrubier, 2002) was administered. Information was gathered on the history of the present illness, past medical history, and client history. The only homework for the client was his selfmonitoring of activities. The three sessions were held on a weekly basis.

In the Treatment Sessions 4 through 12, the core process of ACT treatment was introduced in a step-by-step manner. "Contact the present moment (mindfulness)" was introduced from session 4. "Defusion" was introduced from session 6. In session 7 "Acceptance (willingness)" was introduced. "Clarification of values" was introduced in session 8 , "Committed actions" in session 9, and "Self-as-context" was introduced in session 11. Sessions continued on a weekly basis.

In the Booster Sessions 13 through 15, there was a focus on post-treatment selfmanagement, and a review of the work from Sessions 4 through 12 was conducted with the help of Hayes and Smith's (2005) self-help book Get Out of Your Mind and Into Your Life: The New Acceptance and Commitment Therapy. As homework, the client was assigned the reading of 3 to 4 chapters from the book and was asked to try out exercises in his everyday life. Sessions were held bi-weekly.

Follow-Up Sessions were scheduled each month to review the events of the past month. The Follow-Up Sessions were structured to include completing questionnaires; reviewing homework (when applicable); discussing the topics of a given session; summarizing; and providing a homework assignment. 
Acceptance and Commitment Therapy for "Taro," a Japanese Client

\section{(f) Outcome Measures}

The outcome measures included:

1. Types and frequency of activities: A self-monitoring sheet for activities was employed so that the client recorded his daily activities for a week, every hour on the hour between 5 a.m. and midnight, on a piece of A4 sized paper.

2. Quantity of activities: The client wore the "Calorie Scan" HJA-306-BW Activity Monitor manufactured by Omron Healthcare Co. Ltd. (a small, accurate mobile device with a newlydeveloped algorithm for measuring various daily movements). This device was used in place of a pedometer because it is capable of measuring upper body activities (e.g., cooking).

3. Sleep time: The amount of sleep achieved was recorded on the above activity sheet.

4. Completing standardized questionnaires, including: the Beck Depression Inventory-Second Edition (BDI-II; Koshima \& Furukawa, 2003); the State-Trait Anxiety Inventory (STAI; Mizoguchi, Shimonaka \& Nakazato, 1991); and the General Health Questionnaire-30 items (GHQ-30; Nakagawa \& Taibou, 1996).

\section{(g) Process Measures}

The process measures included:

1. Acceptance and Action Questionnaire-Second Edition (AAQ-II): This questionnaire is a selfreport measure designed to assess experiential avoidance, which is the polar opposite of acceptance; in other words, the questionnaire assesses efforts to avoid, get rid of, suppress, or escape from unwanted private experiences, as conceptualized in ACT (Bond, Hayes, Baer, Carpenter, Guenole, Orcutt, Waltz \& Zettle, 2011). The study used the Japanese translation by Kishita, Yamamoto and Shimada (2008).

2. Cognitive Fusion Questionnaire-28 items (CFQ-28): This questionnaire is a self-report measure designed to assess cognitive fusion as conceptualized in ACT (Dempster, 2009). This study used the Japanese translation by Morimoto, Kumano, Uruwashi, Sasaki, Kanatani \& Nomura (2011).

3. Five Fact Mindfulness Questionnaire (FFMQ): This questionnaire is a self-report measure designed to assess mindfulness and consists of five subscales: observing, describing, acting with awareness, non-judging of inner experience and non-reactivity to inner experience (Baer, Smith, Hopkins, Krietemeyer \& Toney, 2006). This study used the translation by Sugiura, Sato, Ito \& Murakami (2012).

\section{(h) Treatment Integrity}

Treatment integrity was examined using the "Adherence Raters' Manual" in Plumb and Vilardaga (2010). However, this manual was created for treatment research on obsessive 
Acceptance and Commitment Therapy for "Taro," a Japanese Client

compulsive disorder. Items relating to "In Session Exposure" and "Overall Adherence to Project Manual" were therefore not used.

The rater was the second author, who at the time of this case study research was the inhouse psychologist at the clinic. His clinical orientation is based on clinical behavioral analysis. He had 2 years of post-graduate research and clinical experience.

Specifically, following Twohig, Hayes, and Masuda (2006), treatment integrity was assessed by rating tapes from the therapy session on a Treatment Integrity Scale. The results are shown in Table 1, which consists of a grid with the session number as the rows and particular ACT items and related items as the columns. For each session, the quantity and quality of the coverage of each component of ACT was scored as follows: a score of 1 indicates the variable was never explicitly covered; a score of 2 indicates the variable occurred at least once and not in an in-depth manner; a score of 3 indicates the variable occurred several times and was covered at least once in a moderately in-depth manner; a score of 4 indicates the variable occurred with relatively high frequency and was addressed in a moderately in-depth manner; and a score of 5 indicates the variable occurred with high frequency and was covered in a very in-depth manner. (Note that unrated sessions are indicated by a "--."

In the results on the Treatment Integrity Scale are presented in Table 1. Ten of 15 sessions, or $66.7 \%$, are rated. Sessions 1 through 3 (assessment), session 5 (creative hopelessness and defusion), and session 8 (clarification of values) were not audio-recorded and could therefore not be rated. The adherence rating was 3.0 or higher for all the ACT topics except those twocreative hopelessness and values - that were dealt with in the missing sessions 5 and 8 that weren't recorded. Additionally, the score of therapist competence was 4.8 (with 5.0 being a full score). Overall, as shown in the bottom two columns of Table 1, our results were generally equivalent to or better than those reported in Twohig, Hayes \& Masuda (2006).

\section{(i) Confidentiality}

The client was given verbal explanation of the training and research mission of the clinic and was notified concerning the recording of sessions and the dissemination of case materials in the form of a case study. He was asked to sign informed consent forms. In addition, his consent to audiotaping was again confirmed verbally prior to starting the first session; the content of this paper was reviewed by him prior to publication.

\section{THE CLIENT}

Taro, a 30 year-old male, was a full-time employee in a financial corporation with 3500 employees in over 500 branches across Japan. He had been absent because of emotional problems for roughly $50 \%$ of the time over the past four years (see Figure 1). The doctor at his psychosomatic medical clinic (shinryo-naika) diagnosed him with depression. Compared to other corporations of the same size, Taro's company had poorer practices to support the mental-health care of its workers. For example, there were no systems in place for the support of employees returning to work after a leave of absence (such as the now commonplace "commuting 
Acceptance and Commitment Therapy for "Taro," a Japanese Client

rehabilitation" in which workers practice commuting by train at the same time that work starts prior to resuming work). There were no preventative considerations, and awareness within Taro's corporation of mental health problems, including depression, is low. There were no consistent mental health initiatives taken in this corporation, so Taro's superior had no resources beyond his own personal understanding to rely upon.

As a result of the M.I.N.I. mental status evaluation conducted at our clinical psychology clinic, Taro's profile was found to match major depressive episode, present and past. Taro found out about the clinic from a friend who had received ACT treatment here, and he sought out ACT as a treatment of choice.

Taro has a wife who is 30 years old and is a full-time employee. They have a 3 year-old child. According to Taro in the intake session, the marital relationship is good. His wife does not express dissatisfaction about the fact that Taro takes leaves of absence due to depression.

Taro visited the psychosomatic medical clinic biweekly, where he received pharmacological treatment only. He was taking the following medications: amitriptyline (antidepressant) three 25mg tablets daily; amoxapine (antidepressant) four 25mg capsules daily; bromazepam (anti-anxiety medication) three $2 \mathrm{mg}$ tablets daily; ethyl loflazepate (antianxiety/sedative) two 1mg tablets daily; flunitrazepam (hypnotic, prescribed as anti-insomnia medication) $1 \mathrm{mg}$ tablet daily.

\section{GUIDING CONCEPTION WITH RESEARCH AND CLINICAL EXPERIENCE SUPPORT}

\section{Acceptance and Commitment Therapy (ACT)}

ACT is often referred to as a third wave behavior therapy. It employs organically two sets of interventions supporting clients in leading a more meaningful life: acceptance and mindfulness, and commitment and behavior change. In other words, it is quite different in its therapeutic objective from traditional cognitive behavioral therapy, which is designed to change the form and occurrence of unpleasant thoughts and emotions. The primary goal of ACT is to promote psychological flexibility. Psychological flexibility is defined as being able to accept facts and reality as is (without distorting them), without getting too caught up in language (especially, in "past" and "future," and "self" and "others") and being able to live actively and realistically according to one's own values. In order to enhance psychological flexibility, the Hexaflex model is used in therapy, which breaks down the core process into six components: contact the present moment (be here now), defusion (watch your thinking), acceptance or willingness (open up), self-as-context (pure awareness), values (know what matters), and committed action (do what it takes). Harris (2009) explained these as follows: (1) contact the present moment means being connecting with and engaging in whatever is happening in this moment, (2) defusion means learning to distance or detach from inner or private events, (3) acceptance or willingness means opening up and making room for painful inner events, (4) selfas-context means the observing self being aware of whatever we are thinking, feeling, sensing, and doing in any moment, (5) values are the describing how we want to behave on an ongoing 
Acceptance and Commitment Therapy for "Taro," a Japanese Client

Pragmatic Case Studies in Psychotherapy, http://pcsp.libraries.rutgers.edu

Volume 11, Module 2, Article 2, pp. 117-153, 06-12-15 [copyright by authors]

basis, and (6) committed action means taking effective action, directed by own values.

\section{ACT for Depression}

The application of ACT for depressive clients had already begun in the 1980s (Zettle \& Hayes, 1986; Zettle \& Rains, 1989). Since then, ACT has been applied with those individuals whose psychological flexibility is low and whose daily functions are reduced, such as those with chronic pain, obsessive compulsive disorders and eating disorders (Hayes, Luoma, Bond, Masuda \& Lillis, 2006). Since 2000, there have been eight outcome studies on depression (including those studies examining depressed patients with comorbid disorders) that have demonstrated that ACT is as effective, or more effective than traditional CBT (Bohlmeijer, Fledderus, Rokx \& Pieterse, 2011; Forman, Herbert, Moitra, Yeomans, \& Geller, 2007; Forman, Shaw, Goetter, Herbert, Park \& Yuen, 2012; Gaudiano, Nowlan, Brown, Epstein-Lubow \& Miller 2013; Hayes, Boyd \& Sewell, 2011; Petersen \& Zettle, 2009; Wasler, Karlin, Trockel, Mazina \& Taylor, 2013; Zhao, Zhou, Liu \& Ran, 2013). On the website of Division 12 (Clinical Psychology) of the American Psychological Association for Research-supported Clinical Treatments, ACT is recognized as a psychological treatment with modest research support (http://www.psychologicaltreatments.org/).

\section{ACT for Japanese Clients}

In Japan, reimbursement of fees for cognitive therapy and cognitive behavior therapy has been mandated since 2010. One of the driving forces of this change was that the outcome of these therapies has been demonstrated in Japan. The fee for one session paid to a medical doctor is 4,200 yen, of which 1,260 yen, or 30\%, is paid by the patient. The reimbursement is allowed when (a) the patient suffers from a mood disorder, such as depression; (b) a doctor knowledgeable in cognitive therapy and cognitive behavior therapy designs a treatment plan and provides the patient with a sufficiently detailed rationale of treatment; (c) the duration of one session exceeds 30 minutes; (d) the overall number of sessions does not exceed 16; (e) the treatment is administered according to the manual by the Ministry of Health, Labour and Welfare. Current problems in the system include: (a) there are few medical doctors with the skills to conduct therapy according to the treatment manual; and (b) because the doctor's fee is so low and it is often not thought economically feasible to do so, only a very limited number of medical institutes even offer CT and CBT on health insurance. Furthermore, there is no national licensing system for clinical psychologists, who are board certified by the Foundation of the Japanese Certification Board for Clinical Psychologists; because they cannot provide medical care, their services fall outside public insurance programs. (There are, however, political lobbying efforts underway in the National Diet toward the establishment of a national licensure system.)

Amidst the currently growing interest in CT and CBT, ACT is gaining attention for its comparatively longer-term effects. ACT is garnering additional notice in Japan for the similarities it shares with Morita Therapy developed by the Japanese psychiatrist Shoma Morita in 1928 (Hofman, 2008).

Other than the previously mentioned case study by Muto (2012), there is only one other 
Acceptance and Commitment Therapy for "Taro," a Japanese Client

Japanese case study, by Masuda et al. (2008), which reported ACT with a 23 year-old female university student with an eating disorder not otherwise specified. As a result of ACT (a total of 26 sessions), improvement on the "Acceptance and Action Questionnaire-16" (AAQ-16, Bond \& Bunce, 2003) emerged after the $8^{\text {th }}$ session and was maintained thereafter. The score on Mizes Anorectic Cognitions Questionnaire-Revised (MAC-R; Mizes, Christiano, Madison, Post, Seime \& Varnado, 2000), which is an outcome measure for eating disorder symptoms, improved after the $16^{\text {th }}$ session and the gain was maintained. The follow-up, conducted after 18 months, indicated that the client's improvement continued on both scales after the termination of therapy.

\section{ASSESSMENT OF THE CLIENT'S PROBLEMS, GOALS, STRENGTHS AND HISTORY}

\section{History of the Present Illness}

Figure 1 outlines Taro's history of work at his company, a financial corporation with 3500 employees in over 500 branches across Japan. As can be seen, after working at the company for about four years, Taro was out on various leaves of absence for about $50 \%$ of the next four years, before he began the ACT therapy.

When asked about the process leading to the first leave of absence due to depression the client responded, "Well actually, in the beginning I wasn't even aware of it, but my direct boss was burdening me with an inordinate amount of work. At the time I just drove myself into believing that I was simply incompetent." When asked to be more specific, his response was,

This boss, who I answered directly to, was a very mild-tempered person. When I had just joined the company, he used to call me by my first name, 'Hey, Taro, Taro.' and he treated me very kindly. So I couldn't say no to his 'shadow work' - the work that was not my responsibility but his. I even volunteered to do it; I liked him and I didn't want to be devalued. I didn't want to show my weakness, I was thinking then. But because I didn't refuse any of this extra work my workload became heavier and as a consequence there were more and more occasions when I wasn't able to reach my norm. I ended up being reprimanded by another boss. Honestly, I panicked. The more I panicked, the more I got stuck. Gradually I started losing confidence. I worried about it a lot more and I had more sleepless nights. I finally disclosed my worry to my boss. He listened warmly to me. I felt encouraged. But the shadow work wasn't reduced. I just couldn't say no. I didn't want him to dislike me. I was also afraid of confronting him, though I didn't think like this back then. Eventually I was just out of it all day. 'Something is wrong', I felt, so I went to a psychosomatic medical clinic where for the first time I was diagnosed with depression.

\section{The First Leave of Absence (Duration: 9.5 Months)}

When asked how he was during his first leave of absence he responded,

My body felt so heavy and I just didn't feel like doing anything at all. It was like, I was spending most of the day in bed. I remember that when the medication started to kick in, I felt the pressure, like, 'I need to get back to work and catch up on what I've fallen behind in'. But the doctor at the corporation wouldn't give me permission to get back to work ... I was 
Acceptance and Commitment Therapy for "Taro," a Japanese Client

made to extend my leave of absence twice."

After this first leave of absence, Taro returned to work after resting with pharmacological treatment (Figure 1).

When asked about the process leading to the second leave of absence he responded,

When I was back at the office after 9 months of absence, colleagues of the same age cohort who'd been hired at the same time as me were responsible for more complicated work; I felt pressure, and I also felt cowardly and incompetent. My colleagues of the same cohort were also awkward toward me, and I just didn't have anyone to talk to anymore. I wasn't placed for the same role (in the business department with external relations operation). The only task I was given was paperwork. Soon I began to worry about a lot of things and I couldn't sleep well. I was late for work, took half a day off, missed a full day. Even when I did go to the office, I confined myself to the guest reception room, away from the others. When I saw my doctor, he wrote a note saying that I needed a week's rest and I took my second leave of absence.

\section{The Second Leave of Absence (Duration: 1 Month)}

When asked how he spent the second leave of absence he said, "Doing nothing in particular. I thought of it as a short break and I just took medication. But the corporate occupational health physician decided to extend my sick leave, so I went back to the office after one month."

Asked about the process that led to the third absence he responded,

When four months had passed after returning to work, my boss was sent to another branch. I just didn't feel like my personality fit with the new boss. He was very business-like and impersonal, and he didn't try to show any understanding of my depression. The process leading to the third depression was the same as the second. I got a note from my doctor saying that I needed a three-month sick leave. What shocked me was that when I submitted my request for a sick leave, the new boss said things like, "You may not be suited for this job," "You should think of other employment possibilities," and "Even if you try to find another job, no company will take you if you miss every Friday morning to go to see a doctor."

\section{The Third Leave of Absence (Duration: 5 Months)} answered,

When the therapist asked how he spent his days during his third sick leave, the client

During my sick leave, I looked for a psychiatric clinic I could visit on Saturdays in case I got a new job, and I transferred there. In June (two months into the leave of absence), the new doctor gave me permission to return to work. But corporate (the occupational health physician and a person in Human Resources) wouldn't give me their permission. When I tried to negotiate my return, the person from HR told me to write a letter of consent stating that if I needed sick leave again, I would voluntarily resign from the corporation. I did sign 
Acceptance and Commitment Therapy for "Taro," a Japanese Client

the consent form. Around this time I started taking walks.

When asked by the therapist about the process leading to the fourth leave of absence, the client responded, "I was transferred to a different office when I returned to work. This office was closer to my home. But after a few weeks, I fell into the same patterns as the previous returns, and I lasted for only two months."

$\underline{\text { The Fourth Leave of Absence (Duration: } 11 \text { Months) }}$

Asked about how he'd spent his sick leave, the client responded,

After a few months I started to join a rehabilitation program offered by the Japanese Program for Employment of the Elderly, Persons with Disabilities and Job Seekers. I did the seven-column method, an activity chart in cognitive therapy and assertiveness training. I also read several books on depression and cognitive therapy. Even better was that I had a chance to speak to other people troubled by the same thing, and I became close to some of them. The program ended in six months. I was permitted to return to work soon after.

Asked about the process leading to the $5^{\text {th }}$ sick leave he responded,

The corporation set a guideline for me that I was not to have any overtime for 3 months. The flip side of that precaution was that I was only given the type of job no different from what's given to newcomers. My colleagues of the same age cohort had all been promoted, workers who were my junior were doing higher-level jobs, and I just felt inferior. But I tried out what I'd learned in the rehabilitation program and I also consulted with the people I'd met there to continue to work. But I reached my limit. I was doing this simple job for 6 months. I fell into the same bad pattern and after 9 months I couldn't stand it anymore.

\section{Fifth Leave of Absence (Duration: The 3 Months Leading to Attendance at This Clinic)}

Asked how he'd spent time during this period he answered,

I was able to move around a bit. I saw Mr. Suzuki, who I met during the rehabilitation program. Mr. Suzuki successfully returned to work. After the program was completed, he looked for therapy and found ACT on his own. He continued that here for 4 months and he said that it was very good. So I got interested in it and I thought I would like to try it out myself.

\section{Chief Complaints}

When asked about his chief complaints, the client stated, "I want to resolve my recurring depression with ACT." Taro gave credit to both the medication and the rehabilitation program for being somewhat effective in certain ways. However, he spoke of having an expectation that ACT would have other, additional benefits.

\section{Personal History and Medical History}

The client's family of origin consists of Taro and his parents (at the time of intake, both 
Acceptance and Commitment Therapy for "Taro," a Japanese Client

parents were in their fifties). Until elementary school Taro was very observant of his parents' instructions, and he reported having no memory of having been scolded by his parents. He didn't keep any secrets from his parents, and his decisions often reflected his parents' will. Until he reached middle school age, he was very good at making others laugh and was active both in sport and academically. He was a central figure at school and in class; as a result, he was chosen class officer and vice president of the student association.

He joined a sporting club after advancing to high school, but because he also needed to attend cram school it was physically impossible for him to do both; for this reason he quit after a few months. It took a five-hour round trip to commute to his university, so he didn't join any clubs there. Instead, he worked as a tutor at a cram school three times a week.

Despite his arduous commutes, he never imagined living on his own. Taro found his tutoring job very rewarding and had a vague plan to become a school teacher. When he started thinking more concretely about his future employment during his second year at university, discussion of major social issues in Japan such as "monster parents" and the "breakdown of the classroom" were in frequent circulation; as a result, he abandoned teaching as a career path.

He thought this was representative of himself: "Even if there was something I wanted to do, if there was any unpleasant aspect or obstacle I ended up running away from it." Strongly influenced by his father's advice, he chose the financial industry. Ultimately he got a position in a finance company in his hometown. Several months after he started, he met his wife at a welcoming party for new employees. They decided to marry a year later.

Taro reported that he had no medical history. In his second year of high school he missed one week of classes due to a "broken heart." Not wanting to come face to face with the girl at school he stayed away, but he reports not being depressed at that time.

\section{Baseline Psychological Assessment}

The results of outcome assessment at baseline in sessions 1 through 3 indicated that his general health was low and depression moderately high. Both state and trait anxiety were very high. Taro's daily caloric expenditure through activity was 500kcal ( $\mathrm{SD}=94.60)$ on average, which is a lot lower that the national average of 750kcal for the same age group. His average daily naptime was 2 hours a day. These suggested a decreased activity level.

According to the ratings in process measures, his experiential avoidance was average. Cognitive fusion was one standard deviation higher than average, while mindfulness was one standard deviation lower than average. His answers to the values-related questions were abstract and almost always conformed to social norms.

Immediately after the conclusion of session 3, the first author evaluated Taro on ACT's six core processes using the Psychological Flexibility Evaluation Sheet (Hayes, Strosahl \& Wilson, 2012, pp. 127-128). The sheet includes 3 to 5 items for each of the six core processes of ACT described in the Guiding Conception section above. Scoring was recorded on a 10-point 
Acceptance and Commitment Therapy for "Taro," a Japanese Client

scale ranging from 0 (none or very rarely) to 10 (fluent and flexible). The results were as follows: "Contact the Present Moment" (2.0); Defusion (0.2); "Acceptance" (1.0); "Self-ascontext" (1.8); "Values" (0); "Committed Action" (0.6).

\section{CASE FORMULATION AND TREATMENT PLAN}

As a result of assessment at baseline, Taro's psychological flexibility was evaluated as being considerably low, and it was judged that efficacy in applying ACT had a high chance of success. Based on his personal history and the history of the present illness, he tended to accept requests from others whom he trusted without question (cognitive fusion), and to avoid even doing what he wanted to do when the situation was at all unpleasant (experiential avoidance). Furthermore, the above results indicated that his flexibility on all six core processes was uniformly low, which meant that there was no one particular core process from which the intervention should be introduced. However, judging solely on the basis of the questionnaire answered directly by Taro, it was indicated that introducing interventions from either defusion or mindfulness (contact the present moment) would be the most appropriate. In this instance, therefore, the intervention started from mindfulness, which Taro was interested in; it then moved seamlessly on to other core processes based on Hayes, Strosahl, and Wilson (1999, 2012). Exercises and check sheets in Ciarrochi \& Bailey (2008), Harris (2009), and Hayes \& Smith (2005) were used.

\section{COURSE OF TREATMENT}

\section{Sessions 1 Through 3 (Baseline)}

Psychological assessment was conducted in sessions 1 to 3 . The therapist interviewed Taro about his chief complaints, the history of his present illness, past medical history, and personal history. The M.I.N.I. mental status examination was also conducted. First impressions of Taro were that he was neatly dressed and that he communicated with ease; although he was to some extent nervous, he was able to answer questions clearly and succinctly.

Since Taro requested ACT in the first session, the therapist provided a brief overview of ACT treatment and explained that the decision as to whether ACT would be appropriate would be determined on the basis of assessment. In the first session, the activity measurement instrument and activity self-monitoring sheet were presented and assigned as homework. He followed up very well, and brought the sheet to every session. Taro's s favorable responsiveness seemed to reflect more upon high expectations he held as a result of the positive response of his friend (who, as mentioned earlier, had had ACT and recommended it) than on a rapid establishment of the therapeutic relationship. When session 3 was concluded, the therapist explained that ACT treatment was suitable for Taro and that the treatment would be implemented starting the following week. Taro was overjoyed, exclaiming, "I will work really hard at it."

In addition to the aforementioned homework, an exercise for the creation of "Your Suffering Inventory" was presented to Taro (Hayes \& Smith, 2005, pp.12-13). Specifically, the therapist explained the task and the goal. The therapist listened intently to the client in order to 
Acceptance and Commitment Therapy for "Taro," a Japanese Client

establish the therapeutic relationship. Taro's behavioral tendency to be respectful of and compliant with his seniors and with authority figures was evident in his attitude toward the therapist.

\section{Session 4}

Taro completed the homework assignment, Your Suffering Inventory, and brought this to the session where his responses were examined. In regard to answering the questions Taro commented, "It was more difficult to express in words than I expected. I didn't think too deeply, I just put all my worries in it." There were 32 problems listed in the inventory. When sorted by situation and severity, these problems were categorized into: child and family, friends, and "my past." The reactions evoked by these situations were: guilt, anxiety, agitation, and frustration. Taro wanted to escape or avoid these situations. Taro himself commented on this sequence that, "I was able to confirm my pattern that when I encounter difficulties, I just flee." The therapist commented that it is indeed important that he is aware of this pattern.

The primary topic of session 4 was Mindfulness (Connect the Present Moment). The exercise "Drinking Tea" (Hayes \& Smith, 2005; pp. 111-112) was tried out. The client and the therapist made a cup of Japanese tea together, while the therapist helped the client appreciate the tea with all his five senses. During the exercise the therapist explained the close connection between mindfulness and Zen practice, and how Zen monks had codified the tea ceremony. Taro commented after the exercise that he'd never tried such a thing before.

The client agreed to add "Drinking Tea" to his homework, and the therapist gave him an instructional sheet. The other homework included the aforementioned activity record, to which Taro proposed adding a daily 30-minute walk. The two subsequent sessions were postponed due to the winter holiday season.

\section{Session 5}

Taro brought in the completed activity sheet and reported that he had tried the "Drinking Tea" exercise 18 times. Each day Taro had written a few comments on the sheet. The therapist interpreted Taro's attempt to try out the exercise 2 to 3 times a week despite the busy holiday season as being indicative of his high motivation for change. Taro filled out the FFMQ at the beginning of the session, and the score had increased by 7 points over the previous session. Among five facets, the score on "acting awareness" increased by 7 points. Changes in the other four facets were within 4 points (In FFMQ, increase in the score indicates improvement). On the other hand, the AAQ-II score increased by 2 points. The score on the CFQ-28 did not change (decreases in score indicate improvement on both the AAQ and the CFQ).

Looking at the exercise sheet at the beginning of the session, Taro reflected on the "Drinking Tea" exercise. The therapist then said, "This is the Chinese character that represents the concept of mindfulness," and he wrote the character down on a piece of paper (The character 念 meaning 'sense' or 'feeling', is written by combining the character 今 for 'now' above the character 心, for 'heart/mind'). Taro asked, “Is this 念 'nen'?” The therapist responded, “If you 
Acceptance and Commitment Therapy for "Taro," a Japanese Client

pronounce it as 'nen', it can be misinterpreted as having a certain nuance of 'resentfulness' in Japanese." Then, circling each of the characters composing it he said, "Mindfulness means "the heart in the now'. In other words, it means carefully observing what is happening in this moment and what you are feeling as it is, without distorting either one."

The main topics in session 5 were creative hopelessness and defusion. Picking up an item from the Suffering Inventory exercise of session 4, namely, "hearing about the promotions of juniors", the therapist explained the ironic effect of thought suppression and experiential avoidance (being the conceptual opposite of Acceptance), and explained in experiential terms how neither is effective (Hayes \& Smith, 2005; pp.24-31). Using the same topic as an example, the therapist conducted an exercise to facilitate defusion between description and evaluation (fact and interpretation) (Hayes \& Smith, 2005; pp.81-82). Taro commented that he "more or less understood the main message," to which the therapist replied, "It's natural not to understand it all right away. Let's keep trying things out experientially."

A new exercise was tried out called the "email-photo" exercise, in which the client takes a photograph of a "new discovery" with his mobile phone camera during his walks, then sending it to the therapist (this is an original exercise devised by the therapist). The goal of this exercise is to enhance "observing" and "describing" - two facets of mindfulness - and to increase Taro's awareness of the difference between description and evaluation. The therapist explained the exercise saying, "Even along familiar streets there are all sorts of fascinating things and occurrences to be discovered amidst all that we frequently overlook. When you find something like this that catches your attention, take a photograph and send it to me. I'm looking forward to seeing the interesting things you discover." Taro was pleased with this idea, saying, "It sounds really interesting. I will look for various stuff." The therapist explained that he would reply to the email within a day of receiving them with his own impressions of Taro's photos. Other homework included the daily activity log, 30-minutes of daily walking, and the "Drinking Tea" exercise (with reduced frequency).

\section{Session 6}

During the week Taro did the "email-photo" exercise 5 times and "Drinking Tea" twice. At the beginning of session 6 he filled out the Five Fact Mindfulness Questionnaire (FFMQ). His score on the observing facet increased 3 points (small change) from the previous session. There was either no change or some decrease in the scores on the other facets. On the other hand, the score on the Cognitive Fusion Questionnaire-28 (CFQ-28) decreased by 28 points (large change), and the score on the AAQ-II decreased by two (small change).

Reviewing the homework exercises, Taro reported having tried out observing the difference between description and evaluation on several occasions (while waiting for the train to arrive, for example). The therapist praised Taro for performing the exercises so frequently and said, "Please continue to practice them until it becomes habit."

The main topics of session 6 included defusion (with an emphasis on distancing) and mindfulness. Exercises such as "Say the Word 'Milk' as Fast as You Can" (Hayes \& Smith, 
Acceptance and Commitment Therapy for "Taro," a Japanese Client

2005; pp. 72-73), "Labeling Your Thoughts" (Hayes \& Smith, 2005; pp.75-76), "Floating Leaves on a Moving Stream" (Hayes \& Smith, 2005; pp.76-77) were tried out during the session. The first exercise requires that the client repeat the word 'milk' as fast as they can for 40 seconds (for this client, the word was changed to 'ocha', or 'tea'), in order to help the client to detach from the meaning of words. "Labeling Your Thoughts" is an exercise in which the client labels frequent thoughts and feelings in order to externalize them (adding an endearment such as, "my buddy, uncertainty"). In the last exercise, "Floating Leaves on a Moving Stream", the client was asked to imagine looking over an embankment watching leaves flowing by one by one on the surface of a stream, imagining that each leaf carries one of his thoughts or feelings. The therapist cautioned that in this exercise it was important to maintain the same distance between the client and the leaves; if the distance was not maintained the client was asked to restart the exercise from the beginning.

Homework included "Floating Leaves on a Moving Stream," the goal of which was to enhance the client's ability on the two facets of "observing" and "describing," and to facilitate an understanding of the difference between the two. Other homework included: the activity log, 30minutes of walking daily, "Drinking Tea," and the "email photos" exercise.

\section{Session 7}

Taro tried out "Floating Leaves on a Moving Stream" 3 times, "email-photo" 5 times, and "Drinking Tea" 3 times. There was little change from the previous session in the process measure scores. On the other hand, the score on STAI-S (state anxiety) had improved by 7 points, reaching level IV for the first time (Score=46). This result suggested the possibility that Taro was using the "Floating Leaves on a Moving Stream" exercise to reduce unpleasant emotions. Since this use is at a complete variance from the goal of the exercise, the therapist explained that reducing unpleasant emotions was not the purpose of the exercise. Taro disclosed that he had indeed used the exercise as a method for reducing unpleasant feelings. Although the "Leaves" exercise was used for the wrong purpose, this is a frequently occurring misunderstanding, and Taro was not an exception.

The main topic of session 7 was "acceptance and willingness." The exercise for this was "keeping hands submerged in ice water". This is an original exercise by the first author; it was also used in an experimental study by Takahashi, Muto, Tada \& Sugiyama (2002) as a measure of tolerance of physical discomfort. Takahashi et al. (2002) demonstrated that participants who performed the "Floating Leaves" exercise were able to tolerate their hands in ice water this for longer periods of time than those in the control group, providing some experimental evidence for its clinical application. In Flaxman, Blackledge \& Bond (2011), there is an exercise called "Holding an ice cube," which facilitates acceptance. The therapist therefore decided to introduce "Keeping hands submerged in ice water." During the first attempt Taro was able to remain with his hands submerged for just 90 seconds. The therapist then tried the exercise too, keeping his hands submerged for 300 seconds. He explained that he kept his hands submerged with the mindset that he would appreciate what he was experiencing in the now, in this moment, without trying to escape from unpleasant sensations, feelings, thoughts, and without judging whether it was good or bad. Taro commented, "I never imagined one could appreciate discomfort." 
Acceptance and Commitment Therapy for "Taro," a Japanese Client

The same homework was given as in session 6; however, the therapist suggested that Taro do the exercise "Floating Leaves" for more than 15 minutes at a time. Taro agreed, commenting, "That seems a bit long, but I'll try."

\section{Session 8}

Taro tried "Floating Leaves on a Moving Stream" 3 times (but for only 5 minutes each time), "email-photo" 7 times, and "Drinking Tea" 3 times.

At the beginning of session 8 the total FFMQ score was 11 points higher than the score from the previous session, and the score on each of the five facets improved from 1 to 3 points. On the other hand, scores on the AAQ-II and CFQ-28 showed little difference from the previous session. The score on STAI-S (one of the outcome measures) went up to the level it had been at the beginning of session 6 .

The main topic of session 8 was Value Clarification. The exercise is an adaptation of "Survey of Life Principles" (Ciarrochi \& Bailey, 2008), in which the client is asked to categorize 100 basic verbs, each on a card, into groups: (1) categorize the cards into five groups in order of frequency of occurrence; (2) categorize the cards that were in the category for highest frequency of 4 or 5 in the previous step into five groups in terms of the excitement he felt either in doing it or that he feels when thinking about doing it; (3) think of specific actions and activities associated with the cards categorized as 4 or 5; and (4) abstract common elements across specific actions and activities that were raised in step 3. As a result of this exercise the client's value was crystalized as "to please others by talking to and teaching them about what I study and learn." Though he at times struggled with the task, the client categorized the cards carefully. The therapist did not evaluate this categorization but probed by asking, "What is the relationship between this pile and that one? Or are they completely unrelated?" in order to facilitate the categorization. In addition to the homework given in session 7 , the therapist proposed that the client consciously perform actions based on this value exercise and record the results.

\section{Session 9}

Session 9 was postponed by a week. The client performed actions based on the value exercise 14 times, "Floating Leaves on a Moving Stream" 8 times, and "Drinking Tea" 6 times over the two week interval.

Among the process scales that Taro filled at the beginning of session 9, the total score of the FFMQ exceeded the average for the first time. There were improvements on all outcome measures. The score on BDI-II reached 9 (in session 8 , the score was 17), which was within the normal range for the first time.

The main topic of session 9 was committed action and the expansion of action. Based on the activity record used in the homework, the therapist and client discussed situations in which the client could take action based on his values, breaking down those actions into smaller, more specific components that could be performed in small steps. Furthermore, the therapist explained 
Acceptance and Commitment Therapy for "Taro," a Japanese Client

the cycle of articulating a plan of action> execution>examination of the result >reexamination of the plan>execution of actions based on the revised plan.

Homework for the week included the execution of committed action based on values and recording of the result.

\section{Session 10}

The client executed committed actions as assigned in the homework 21 times (three actions daily). However, these actions were very similar to ones provided as examples by the therapist in the previous session. The therapist interpreted this as an indication of inflexibility. Taro performed "Floating Leaves on a Moving Stream" 3 times, "email-photo" 6 times, and "Drinking Tea" twice.

Scores on the process scales were unchanged from those of the previous week. On the other hand, the score on the BDI-II, which is one of the outcome scales, was 4, which was even lower than the previous week. The score on STAI-S decreased to fit within the level IV range (high level).

Based on the homework results, the main topic of session 10 was set as the same one from the previous week. The therapist guided the client to come up with new ideas about committed action based on his own values.

\section{Session 11}

Taro tried out the committed action homework ( 3 actions a day) 21 times. His committed actions included both actions based on his personal values and ones that he had thought unpleasant; improvement over the previous week was seen. He performed "Floating Leaves on a Moving Stream" 3 times and "Drinking Tea" twice.

Among the process scales Taro completed at the beginning of session 11, the score on CFQ-28 went down to 14 points and was, for the first time, lower than the average. The score on AAQ-II decreased by 3 points (the maximum reduction seen so far), and was also lower than the average for the first time. On the other hand, the score on the BDI-II outcome measure was 3, which was even lower than the previous session. The score on the STAI-T decreased to level IV (high level) for the first time. Indeed, there was a sense of comfort observed in Taro's facial expression during therapy, and he commented it felt like what he had achieved so far through therapy was being integrated.

The main topic of the session was the "Hexaflex," that is, the whole core process, including Self-As-Context, which was not introduced in previous sessions 4 through 10. "Hexaflexercise" (Harris, 2009; pp.43-49) was tried out. This is an experiential exercise involving deep breathing and meditative components. After the exercise, the therapist informed the client that in the future he would be using the Hexaflex sheet for self-management. The proposed homework was the same as that in session 10 . 
Acceptance and Commitment Therapy for "Taro," a Japanese Client

\section{Session 12}

Taro conducted the proposed homework, committed action, 21 times ( 3 actions daily) consistently. It included 3 new actions that had not been attempted previously. He performed "Floating Leaves on a Moving Stream" 3 times, "email-photo" exercise 7 times, and "Drinking Tea" twice.

Among the process scales Taro filled out at the beginning of the session, the FFMQ score was one standard deviation above the mean. On the other hand, scores on the outcome measures showed little change.

The main topic of session 12 was Hexaflex-based self-management. The therapist explained through examples a method of examining which of the six core processes were responsible for unsuccessful aspects of a day's activities, and methods for identifying strengths and weaknesses while recording daily activities on the log. The therapist also proposed that intensive treatment be terminated and that bi-weekly booster sessions commence the following week, along with self-management based on the Hexaflex sheet and bibliotherapy using a translation of Hayes \& Smith (2005). The effectiveness of this translation for enhancing health in college studies was demonstrated in Muto, Hayes \& Jaffcoat (2011). Taro readily consented to this proposal.

Taro was assigned the same homework as in session 11 along with assigning him to read chapters 1 through 3 of the translation of Hayes \& Smith (2005).

\section{Session 13 (Booster Session 1)}

Taro consistently performed the homework assignments, as he had done in previous weeks. During the daytime he went to a library near his home and read chapters 1 through 4 of Hayes \& Smith (2005) and did paperwork. Also during this two-week period, Taro visited his place of work with a graph of his BDI-II scores over time, which the therapist had prepared. Taro reported feeling a boost in confidence when his boss said that he looked healthier.

Among the process scores that Taro filled out at the beginning of session 13, the FFMQ score improved further and the score on CFQ-28 did also. Moreover, the outcome scale scores maintained a good level.

The main topics of session 13 were a discussion of the chapters of Hayes \& Smith (2005). Taro had read, and the introduction of the Psychological Flexibility evaluation form (Hayes et al., 2012). This evaluation sheet was introduced to facilitate the execution of self-management based on the hexaflex.

First, Taro declared that he had trouble understanding the concept of willingness and asked that it be explained. The therapist asked Taro to try jumping up from his chair and then simply stepping away from it, and asked Taro to observe and discuss the difference between the two actions (Hayes \& Smith, 2005, p.136). 
Acceptance and Commitment Therapy for "Taro," a Japanese Client

In introducing the psychological flexibility evaluation form, the therapist explained each item briefly and Taro was asked to evaluate each of them one by one, since the sheet is made for professionals and the written explanation was therefore difficult to understand.

Scores (on a rating from $1=$ lowest to 10-highest) on his self-reported psychological flexibility for each subscale were as follows: 8.7 for Contact the Present Moment; 8.4 for Defusion; 8.7 for Acceptance; 8.0 for Self-as-context; 9.2 for Values; 9.0 for Committed Action. However, the therapist also rated the same scale at the beginning of the session and those scores were: 7.3 for Contact the Present Moment; 8.6 for Defusion; 8.7 for Acceptance; 7.0 for Self-asContext; 9.8 for Values; 9.2 for Committed Action. Here, In this Moment and Self-as-Context were the two subscales in which there was a discrepancy between therapist and client ratings of more than 1 point.

The same homework was assigned; Taro was asked to read chapters 5 through 8 of Hayes \& Smith (2005).

\section{Session 14 (Booster Session 2)}

As in previous weeks, the homework assignment was performed consistently, and Taro also read chapters 5 through 8 of Hayes \& Smith (2005). Taro reported having had a meeting at his workplace to discuss his return, and he reported that he was able to voice his preferences during the interview. He also commented that he felt anxious because he didn't hear the outcome of the interview right away.

The total score on the FFMQ improved further, as did the CFQ-28. The score on the STAI-T went down to Level III (normal level), but the score on the STAI-S remained in the high range.

The chief topic of session 14 was a discussion of the chapters of Hayes \& Smith (2005) that Taro had read over the previous fortnight. Taro asked questions about the difference between experiential avoidance and defusion, and also about self-as-context. For the first question, the therapist explained the difference by referencing chapter 2, particularly Figure 2.4 (p. 31) of Hayes \& Smith (2005). The figure consists of concentric circles, with "natural pain" in a black center circle and then additional pain being created in the larger circles as language keeps us amplifying these difficulties into larger patterns of suffering. Like the rings around the black center in Figure 2.4, we build out that core of pain by our patterns of cognitive entanglement and avoidance" (p. 31).

The therapist answered the self-as-context question by referring to "The Chess Metaphor" (p. 96-97 of chapter 7, Hayes \& Smith (2005) and using actual chess pieces during the explanation. In this metaphor,

each of the pieces represents a different emotion, cognition, memory, or sensation. Some of the pieces are positive, such as happiness, joy, pleasurable feelings, and loving memories. They hang together as a team. And some of the pieces represent your pain, fears, and failings ... [and] these conditions hang out together as a team ... Now imagine that the 
Acceptance and Commitment Therapy for "Taro," a Japanese Client

various pieces start doing battle. It is a long, bloody war and pieces are being hewn and smashed to bits all around you" (p. 96).

This metaphor is then continued, with the client eventually realizing that he can extend his vision beyond the battle of the chess pieces and can then see the self as the chess board. In other words, "To start seeing matters from the perspective of the board is to get in touch with the observing self" (p. 97).

The same homework was assigned, including the reading of the remaining chapters of Hayes \& Smith (2005).

\section{Session 15 (Booster Session 3)}

As always, Taro consistently completed the homework assignments, and he finished reading Hayes \& Smith (2005). He reported that the date for his return to work had been determined; it was scheduled to take place in 5 days' time. The therapist asked, "Are you anxious about it?" to which Taro replied, "Of course I do have some anxieties, but I can distance myself from the anxiety as I've been learning to do with ACT, so I think I'll be fine."

Among the process scales that he'd filled out at the beginning of session 15, the scores on the AAQ-II and the CFQ-28 had both improved further, reaching about one standard deviation below the mean. On the other hand, as shown in Figure 2, scores for the outcome measures showed little improvement. Also as shown in Figure 2, overall this meant that the score on STAI$\mathrm{S}$ (state anxiety) was the only score that did not reach the average level by the end of sessions.

The main topic of session 15 was making use of ACT after returning to work. Specifically, the therapist proposed that he review his week and make necessary adjustments using the Psychological Flexibility sheet (Hayes et al., 2012) each Friday. Taro accepted this proposal.

The therapist and the client agreed that they would meet monthly for follow-up sessions after Taro's return to work.

\section{Session 16 (Follow-up Session 1)}

Taro had returned to work, but he had not been assigned much actual, substantial work to do (as an example of this, he was not even provided with a computer to work on). As a result of this he felt despondent and after having worked the first 4 days he took a day off, saying that he felt unwell. Taro sent an email to the therapist explaining the situation and requesting an appointment. Even though it was two weeks before the next scheduled session, the therapist met with him the day after the email exchange.

At the beginning of the session, Taro was asked to complete all of both the process and the outcome measures. The scores were all similar to those from the beginning of session 11 . More specifically, although depression and anxiety had worsened since the final booster session, psychological flexibility had not deteriorated. 
Acceptance and Commitment Therapy for "Taro," a Japanese Client

During the session the therapist asked for a detailed account of what had transpired on each day of the five days Taro spent at the office, from the first day back at work until the last. Using that information as a basis, the client and the therapist looked for opportunities for Taro to perform actions based on his values, and they discussed concrete ways to request improvements to his workplace situation of his boss. Taro's facial expression brightened when coming up with concrete ways to do this, and he said, "There's no point sulking; I'm going to try doing whatever I can." The next meeting was scheduled for one month later.

\section{Session 17 (Follow-up session 2)}

The session was held one month after the previous, as scheduled. At the beginning, Taro was asked to fill out all of the process measures and all the outcome measures.

Taro reported that 10 days prior to the session, he had spent five days in hospital for an appendectomy. His surgeon had apparently told him that there was a possibility that the large variety and quantity of psychotropic he'd been prescribed at the psychosomatic medical clinic were apt to cause constipation and thus were implicated in his appendicitis. Also, at work his boss informed him that he had only three days' paid sick leave left; he was warned that once these had been used up, Taro would have to take an automatic leave of absence.

At work, Taro still had not been assigned work of much significance (at this point, he still had not been given a computer). Even though he had been granted permission to return to work, this state of affairs was both strange and unusual, and likely was indicative of workplace harassment. However, the corporation had no mechanism for appealing this sort harassment.

During this session, as in the previous one, the therapist asked for details of each individual workday. The client and the therapist then collaboratively looked for opportunities for making values-based actions, and they discussed concrete ways of requesting that his boss make improvements to his work situation. The therapist suggested that they being meeting bi-weekly again, but Taro responded that he couldn't do that as he had only three days' paid leave left. The next session was therefore scheduled for a months' time.

\section{Session 18 (Follow-up Session 3)}

The session was held as scheduled. There was almost no improvement on either the process or the outcome scales; scores were maintained at the levels from the previous session.

The range of tasks at work was widening, but Taro reported ruminating obsessively when he compared his own work content and performance to those of his peers and juniors.

The physician at the psychosomatic medical clinic added a prescription for the antidepressant sertraline (two 25mg tablets daily) to Taro's drug regimen. Asked if he noticed any change from this addition, Taro reported feeling a bit dull and heavy, but the therapist did not note any particular change in the client.

During the session the therapist explained that ruminating is an avoidant reaction, and 
Acceptance and Commitment Therapy for "Taro," a Japanese Client

once again he confirmed with the client the ACT method of dealing with this. As before, Taro was asked to describe in detail his every work day from beginning to end, and together the client and therapist looked for ways to perform actions based on Taro's values. The next session was set for one month's time.

\section{Session 19 (Follow-up Session 4)}

The scheduled session was cancelled because the client had a cold; the session was instead conducted one and a half months after the previous session. One week prior to session 19, Taro had begun another leave of absence. Because he had used up all of his paid vacation time, he was instructed to take another leave of absence. This meant that he had returned to work for only three months total in the previous year. All scores on both the process and outcome scales reverted to what they had been in session 8 .

At this point it was suspected that Taro's sense of fatigue was due to overmedication with various psychotropic drugs. He was planning to undergo an inpatient detox treatment. He requested a continuation of psychotherapy. The therapist consented, seeing value after the inpatient detox treatment.

\section{THERAPY MONITORING AND USE OF FEEDBACK INFORMATION}

The therapy was monitored by a careful review of all measures described above in each session after it occurred, with resultant ideas about how to revise and guide the therapy course based on the hexaflex model. The therapist, the first author, reviewed and discussed the progress of once every 2 sessions with the second author in peer-supervision.

\section{CONCLUDING EVALUATION OF THE TREATMENT'S PROCESS AND OUTCOME}

\section{Process and Outcome Results}

Figure 2 shows time series change of scores on outcome measures. The top part shows BDI-II and GHQ-30 scores, the middle part shows STAI-T score, and the bottom part shows the STAI-S score. The score on BDI-II and GHQ-30 started to come down when the intervention was introduced (Session 4). Furthermore, after interventions on value clarification and committed action were introduced the scores dropped drastically, and were maintained at a stable level even after shifting to booster sessions.

In the follow-up period after the client returned to work the scores worsened, yet remained below the score of session 9. However, in session 19 when the client had taken another leave of absence, the scores on BDI-II and GHQ-30 went beyond the cutoff level. The middle graph shows that STAI-T did not change from the time intervention was introduced up until session 8. However, after session 8 the score gradually decreased, reaching Level 4 in session 11. The score dropped further to Level 3 during the booster sessions. The score went up in the 
Acceptance and Commitment Therapy for "Taro," a Japanese Client

follow-up sessions after returning to work; however, it never increased past the point it had been in session 9. The score did not change in session 19, when he took another leave of absence.

The score on the lower part of the graph representing STAI-S did not change until session 6. It dropped drastically in session 7, but increased again in session 8 . The score then gradually decreased until session 10 , when the score reached level 4 . The score was stabilized in the booster sessions. In the follow-up period after the client had returned to work the score increased once more, but it never exceeded the score of session 9.

Based on the results on the four outcome measures, it can be concluded that ACT treatment improved this patient's symptoms of depression and anxiety over the course of therapy, especially after he initially went back to work. Additionally, the gains were maintained after his returning to work despite unfavorable working conditions. Even during the second leave of absence between sessions 18 and 19, depressive symptoms and trait anxiety were maintained at a good level compared to the scores when he initially sought treatment.

Figure 3 shows changes of process scale scores over time. The graph in the upper part shows the scores of FFMQ (Mindfulness or Contact the present moment), the graph in the middle part shows the scores on CFQ-28 (Cognitive Fusion), and the graph in the lower part shows scores on the AAQ-II (Experiential avoidance, or the polar opposite of Acceptance). The score on Mindfulness improved gradually after the introduction of treatment. In the booster session period, the score remained within one standard deviation above the mean. The score went down somewhat in the follow-up period after the client returned to work, but it still remained at a high level. An average level was maintained when the client took another leave of absence just before session 19.

Cognitive defusion, seen in the middle part of the graph, is scored so that lower scores indicate less fusion, i.e., greater defusion. The graph shows that cognitive defusion improved dramatically after the introduction of intervention and in the booster session period, the score reaching one standard deviation below the mean. The score went up somewhat in the follow-up period when the client returned to work, but it remained at a level below the baseline.

Experiential avoidance (the polar opposite of Acceptance), in the lower part of the graph, is also scored so that lower scores are healthier, in this instance indicating less avoidance or more Acceptance. The graph shows that experiential avoidance started to gradually improve before the treatment phase started and it continued going down after treatment had begun. The improvement continued after the start of the booster sessions, reaching one standard deviation below the mean in session 15. The score worsened somewhat in the follow-up period, but it was still within average range.

Based on the results of the three process measures, it was demonstrated that the aspect "mindfulness and acceptance" according to ACT was improved by treatment and that these treatment gains were maintained. Furthermore, interventions aimed at specific core processes were effective in the manner hypothesized. Even when the client went on the leave of absence at session 19 the three scores were within average range, as indicated in Figure 3. Dramatic 
Acceptance and Commitment Therapy for "Taro," a Japanese Client

deteriorations of depressive symptoms and anxiety were prevented.

Figure 4 presents the transitions in average daily activity level measured with a pedometer. A nonparametric test revealed a statistically significant trend in changes of activity level between session 2 and $15(p<.001)$. Visual inspection of the graph clearly indicates incremental changes showing the client's increased activity during the intervention phase. Furthermore, his daily activity level, which had been approximately $500 \mathrm{kcal}$ in the baseline period, had increased to between 600 and $750 \mathrm{kcal}$ in the booster session period. This change in activity level is equivalent to preparing two meals, playing the piano for 30 to 40 minutes, or jogging for 15 to 20 minutes. It appeared that the client's activity level increased after session 8 , which focused on increasing and expanding activity. Therefore, by dividing the sessions into two groups (before session 8 and after session 8) and using this as a fixed factor and by using time as a covariate, the difference in the angle of the slopes in the two groups was tested using general linear modeling. The result, however, was non-significant $(F(1,131)=0.226, p=0.635)$ and there was no statistically significant difference in the angle of the two slopes. Thus it was suggested that it was not the treatment focusing on committed action specifically that caused an increase in the client's activity level.

Figure 5 shows changes to the client's nap times. His naps between sessions 2 and 15 might have changed after session 8 , when the therapeutic focus was on increasing and expanding committed action. Therefore, by dividing sessions into two groups (before session 8 and after session 8) and using this as a fixed factor and time as a covariate, the difference in the angle of the two slopes in the two groups was tested using a general linear modeling. The result was significant $(F(1,131=210.51, p<0.01)$. Thus it was suggested that it was specifically the treatment focusing on committed action that reduced the duration of nap times.

Table 2 presents Reliable Change Indexes for this case (Values presented are the comparisons between pre-treatment and post-treatment, between pre-treatment and the third booster session, and between pretreatment and fourth follow-up session). First, the comparison between pre-treatment and post-treatment outcomes revealed reliable positive changes in all outcome measures except AAQ-II. In particular, the size of change on BDI-II and GHQ-30 exceeded two standard deviations. Based on these results, it is concluded that the client demonstrated clinically reliable and significant change in depression and general health status. It is also further suggested that these changes were due to the improved mindfulness.

Next, the comparison between pre-treatment and the third booster session (T3-T1) revealed clinically significant changes in all measures. In particular, the size of the changes on BDI-II, GHQ-30, STAI-T, FFMQ, and CFQ-28 exceeded two standard deviations. These results indicated that significant improvements in depressive symptoms, general health status, and trait anxiety were made. They also suggest that the facilitation of mindfulness, acceptance, and defusion triggered these changes. At the final follow-up, significant changes were maintained on BDI-II, GHQ-30, STAI-T, FFMQ, and CFQ-28. However, the score on GHQ-30 dropped significantly. The fact that general health status deteriorated in spite of changes in depressive symptoms and trait anxiety while mindfulness and defusion were maintained suggests the possibility that problems with the work environment and over-medication both played a role. 
Acceptance and Commitment Therapy for "Taro," a Japanese Client

\section{Case Comparison with Muto (2012)}

In the current case study and Muto (2012), the same therapist conducted the same form of ACT in the same therapy room with two clients who had very similar complaints. The treatment was similar in length and the session frequency was also similar. The same outcome measures were used (e.g., In Muto (2012), only BDI-II, GHQ-30, and AAQ-II were used).

The reliable change indexes in Muto (2012) were significant for all three scales comparing the pretreatment scores against post-treatment (T2-T1), third booster session (T3-T1), and the fourth follow-up session (T4-T1). Specifically, for BDI-II, reliable change indexes were 5.63(T2-T1), 4.22(T3-T1), and 6.57(T4-T1); for GHQ-30, 10.13(T2-T1), 5.06(T3-T1), and 10.97(T4-T1); and for AAQ-II, 4.03(T2-T1), 5.29(T3-T1), and 4.28(T4-T1). In both the present case study and Muto (2012), significant improvement on BDI-II and GHQ-30 was observed at post-treatment and improvement for BDI-II was maintained until the next follow-up, which was 3 months after termination. In other words, these two case studies indicate that ACT is effective in improving depression. On the other hand, the client in Muto (2012) maintained changes on both GHQ-30 and AAQ-II. The improvement on AAQ-II was significant from post-termination. This difference may be due to vastly different working environments: The client in Muto (2012) worked for a corporation that advocated improvement of mental health conditions. Upon returning to work after a leave of absence, the in-house doctor and the client's manager periodically held interviews with the client and arranged a gradual increase in the amount of work that he took on. On the other hand, Taro, the client in this study, received no such arrangement or consideration. He was not given a computer or telephone at his desk. It is possible that acceptance was not sufficiently facilitated in this case. In the future, it is necessary to examine the relationship between the successfulness of the acceptance task and outcome.

\section{Social Validity}

In Figure 2 and 3, scores on all the process scales and STAI are shown with the average scores for Japanese adults on each scale presented, with the range of one standard deviation above and below the mean (Kendall, Marrs-Garcia, Nath \& Shledrick, 1999). The client's scores on all scales reached the mean or one standard deviation above the mean by session 12 .

During the booster session period, the therapist submitted a therapeutic progress report, including a synopsis of sessions and a graph showing changes of BDI score over time, to the occupational health doctor at Taro's corporation at Taro's request. The doctor commented, "You have been receiving proper psychotherapy."

One year after the completion of the booster sessions, an email was sent to both Taro and his wife asking them to evaluate their satisfaction with the treatment on a 5 - point scale (5=very satisfied, 4=satisfied, $3=$ neither satisfied nor dissatisfied, 2=dissatisfied, $1=$ very dissatisfied). The questionnaire items were: (a) How satisfied are you with the procedure and content of Acceptance and Commitment Therapy (ACT)? (b) How satisfied are you with the therapist? (c) How satisfied are you with the fee for a single session (2500 yen)? (d) How satisfied are you with the session frequency and length of treatment? , and (e) How strongly would you 
Acceptance and Commitment Therapy for "Taro," a Japanese Client

recommend ACT to those people in similar situations? (5=very strongly, 4=strongly, $3=$ neither strongly recommend nor not recommend, $2=$ would not recommend, $1=$ would strongly not recommend). Taro's responses to these questions were 4, 5, 5, 5, 4. His wife's responses were 4, $5,5,4,3$. Her reason for the lower rating on (e) was, "Because I didn't receive therapy.” Judging from the overall results of these scores, it is suggested that the treatment was socially valid.

\section{Limitations and Future Directions}

This study was successful in evaluating changes on each of the six core processes over time and demonstrating how these changes in core processes directly contributed to the improvement of depression and anxiety symptoms, and it improved the scientific quality of case study research design. However, some of the limitations include: that the client's improvements were not maintained during follow-up; that the contributing factors could not be fully identified; that there was an insufficient number of sessions; and that there was workplace intransigence (for example, after returning to work the client was not allowed use of a computer necessary for him to do his job).

This study demonstrated that ACT treatment can be effective with Japanese clients, suggesting that ACT may be a cross-culturally effective treatment modality. However, this study did not empirically test which specific procedures are required to accommodate cultural characteristics unique to Japanese clients. Future directions include testing the above limitations in an analogue design (Levin, Hildebrandt, Lillis \& Hayes, 2012), because it is difficult to test these in the context of naturalistic case studies. 
Acceptance and Commitment Therapy for "Taro," a Japanese Client

\section{REFERENCES}

Baer, R. A., Smith, G. T., Hopkins, J., Krietemeyer, J., \& Toney, L. (2006). Using self-report assessment methods to explore facets of mindfulness. Assessment, 13, 27-45.

Bohlmeijer, E. T., Fledderus, M., Rokx, T. A., \& Pieterse, M. E. (2011). Efficacy of an early intervention based on acceptance and commitment therapy for adults with depressive symptomatology: Evaluation in a randomized controlled trial. Behaviour Research and Therapy, 49, 62-67.

Bond, F. W., \& Bunce, D. (2003). The role of acceptance and job control in mental health, job satisfaction, and work performance. Journal of Applied Psychology, 88, 1057-1067.

Bond, F. W., Hayes, S. C., Baer, R. A., Carpenter, K., M., Guenole, N., Orcutt, H. K., Waltz, T., \& Zettle, R. D. (2011). Preliminary psychometric properties of the Acceptance and Action Questionnaire-II: A revised measure of psychological inflexibility and experiential avoidance. Behavior Therapy, 42, 676-688.

Ciarrochi, J. \& Bailey, A. (2008). A CBT-Practitioner's guide to ACT: How to bridge the gap between cognitive behavioral therapy and Acceptance and Commitment Therapy. Oakland, CA: New Harbinger Publications.

Dempster, M. A. (2009). The development and initial validation of a scale to measure cognitive fusion. The university of Edinburgh.

Flaxman, P. E., Blackledge, J. T., \& Bond, F. W. (2011). Acceptance and commitment therapy: The CBT distinctive features series. Hove: Routledge.

Forman, E. M., Herbert, J. D., Moitra, E., Yeomans, P. D., \& Geller, P. A. (2007). A randomized controlled effectiveness trial of Acceptance and Commitment Therapy and Cognitive Therapy for anxiety and depression. Behavior Modification, 31, 772-799.

Forman, E. M., Shaw, J. A., Goetter, E. M., Herbert, J. D., Park, J. A., \& Yuen, E. K. (2012). Long-term follow-up of a randomized controlled trial comparing acceptance and commitment therapy and standard cognitive behavior therapy for anxiety and depression. Behavior Therapy, 43, 801-811.

Gaudiano, B. A., Nowlan, K., Brown, L. A., Epstein-Lubow, G., \& Miller, I. W. (2013). An open trial of an acceptance-based behavioral psychotherapy for major depression with psychotic features. Behavior Modification, 37, 324-355.

Harris, R. (2009). ACT made simple: An easy-to-read primer on Acceptance and Commitment Therapy. Oakland, CA: New Harbinger.

Hayes, L., Boyd, C. P., \& Sewell, J. (2011). Acceptance and Commitment Therapy for the treatment of adolescent depression: A pilot study in a psychiatric outpatient setting. Mindfulness, 2, 86-94.

Hayes, S. C., Barlow, D. H., \& Nelson-Gray, R. O. (1999). The Scientist practitioner: Research and accountability in the age of managed care $\left(2^{\text {nd }} . E d\right.$.) Boston: Allyn \& Bacon.

Hayes, S. C., Luoma, J., Bond, F., Masuda, A., \& Lillis, J. (2006). Acceptance and Commitment Therapy: Model, processes, and outcomes. Behaviour Research and Therapy, 44, 1-25.

Hayes, S. C., \& Smith, S. (2005). Get out of your mind and into your life: The new Acceptance and Commitment Therapy. Oakland, CA: New Harbinger.

Hayes, S. C., Strosahl, K.D., \& Wilson, K. G. (1999). Acceptance and Commitment Therapy: An experiential approach to behavior change. New York: The Guilford Press.

Hayes, S.C, Strosahl, K.D., \& Wilson, K.G. (2012). Acceptance and commitment therapy: The 
Acceptance and Commitment Therapy for "Taro," a Japanese Client

with Chronic Depression: A Replicated Treatment-Evaluation

T. Muto \& T. Mitamura

Pragmatic Case Studies in Psychotherapy, http://pcsp.libraries.rutgers.edu

Volume 11, Module 2, Article 2, pp. 117-153, 06-12-15 [copyright by authors]

process and practice of mindful change (2nd edition). New York: The Guilford Press.

Hofman, S. G. (2008). Acceptance and commitment therapy: New wave or Morita Therapy? Clinical Psychology: Science and Practice, 15, 280-285.

Jacobson, N. S., \& Truax, P. (1991). Clinical significance: A statistical approach to defining meaningful change in psychotherapy research. Journal of Consulting and Clinical Psychology, 59, 12-19.

Kendall, P. C., Marrs-Garcia, A., Nath, S. R., \& Sheldrick, R. (1999). Normative comparisons for the evaluation of clinical significance. Journal of Consulting and Clinical Psychology, 67, 285-299.

Kishita, N., Yamamoto, T., \& Shimada, H. (2008). Developing Japanese version of Acceptance and Action Questionnaire-II. [Japanese]. Paper presented in the $21^{\text {st }}$ Annual Convention of Japanese Association of Health Psychology.

Koshima, M. \& Furukawa, T. (2003). Japanese version of Beck Depression Inventory-Second Edition. Tokyo: Nihon Bunka Kagakusha Co., Ltd.

Levin, M. E., Hildebrandt, M. J., Lillis, J., \& Hayes, S. C. (2012). The impact of treatment components suggested by the psychological flexibility model: A meta-analysis of laboratory-based component study. Behavior Therapy, 43, 741-756.

Masuda, A., Muto, T., Hayes, S. C., \& Lillis, J. (2008). Acceptance and Commitment Therapy: Application to a Japanese client. [Japanese]. Japanese Journal of Behavior Therapy, 34, 137-148.

Mizes, J. S., Christiano, B., Madison, J., Post, G., Seime, R., \& Varnado, P. (2000). Development of the Mizes Anorectic Cognitions Questionnaire-Revised: Psychometric properties and factor structure in a large sample of eating disorder patients. International Journal of Eating Disorders, 28, 415-421.

Mizoguchi, K., Shimonaka, J., \& Nakazato, K. (1991). Japanese version of State-Trait Anxiety Inventory (Form X). Kyoto: Sankyobo Co., Ltd.

Morimoto, K., Kumano, H., Uruwashi, M., Sasaki, R., Kanatani, N., \& Nomura, S. (2011). Developing Japanese version of Cognitive Fusion Questionnaire-28. [Japanese]. Paper presented in the $37^{\text {th }}$ Annual Convention of Japanese Association of Behavior Therapy.

Muto, T. (2012). A treatment-evaluation of Acceptance and Commitment Therapy for an adult with chronic depression: Toward bridging between traditional case reports and randomized controlled trials. [Japanese]. Japanese Journal of Psychosomatic Medicine, 52, 810-818.

Muto, T., Hayes, S. C., \& Jeffcoat, T. (2011). The effectiveness of Acceptance and Commitment Therapy bibliotherapy for enhancing the psychological health of Japanese college students living abroad. Behavior Therapy, 42, 323-335.

Nakagawa, Y. \& Taibou, I. (1996). Japanese version of General Health Questionnaire-30. Tokyo: Nihon Bunka Kagakusha Co., Ltd.

Petersen, C. L \& Zettle, R. D. (2009). Treating inpatients with comorbid depression and alcohol use disorders: A comparison of acceptance and commitment therapy versus treatment as usual. The Psychological Record, 59, 521-536.

Plumb, J. C. \& Vilardaga, R. (2010). Assessing treatment integrity in Acceptance and Commitment Therapy: Strategies and suggestions. International Journal of Behavioral Consultation and Therapy, 6, 263-295.

Sheehan, D. V. \& Lecrubier, Y. (2002). The Mini-International Neuropsychiatric Interview 
(5.0.0). Jacksonville, FL: Medical Outcome Systems, Inc.

Sugiura, Y., Sato, A., Ito, Y., \& Murakami, H. (2012). Development and validation of the Japanese version of the Five Facet Mindfulness Questionnaire. Mindfulness, 3, 85-94.

Takahashi, M., Muto, T., Tada, M., \& Sugiyama, M. (2002). Acceptance rationale and increasing pain tolerance: Acceptance-based and FEAR-based practice. [Japanese]. Japanese Journal of Behavior Therapy, 28, 35-46.

Twohig, M. P., Hayes, S. C., \& Masuda, A. (2006). Increasing willingness to experience obsessions: Acceptance and Commitment Therapy as a treatment for obsessive compulsive disorder. Behavior Therapy, 37, 3-13.

Walser, R. D., Karlin, B. E., Trockel, M., Mazina, B., \& Taylor, C. B. (2013). Training in and implementation of Acceptance and Commitment Therapy for depression in the Veterans Health Administration: Therapist and patient outcomes. Behaviour Research and Therapy, 51, 555-563.

Zettle, R. D., \& Hayes, S. C. (1986). Dysfunctional control by client verbal behavior: The context of reason giving. Analysis of Verbal Behavior, 4, 30-38.

Zettle, R. D., \& Rains, J. C. (1989). Group cognitive and contextual therapies in treatment of depression. Journal of Clinical Psychology, 45, 438-445.

Zhao, W., Zhou, Y., Liu, X., \& Ran, L. (2013). Effectiveness of acceptance and commitment therapy on depression. [Chinese]. Chinese Journal of Clinical Psychology, 21, 153-157. 
with Chronic Depression: A Replicated Treatment-Evaluation

T. Muto \& T. Mitamura

Pragmatic Case Studies in Psychotherapy, http://pcsp.libraries.rutgers.edu

Volume 11, Module 2, Article 2, pp. 117-153, 06-12-15 [copyright by authors]

Table 1. Rating Results of the Treatment Integrity Scale in ACT for This Study and for Twohing, Hayes, \& Masuda (2006).

\begin{tabular}{|c|c|c|c|c|c|c|c|c|c|c|c|c|}
\hline & \multirow{2}{*}{$\begin{array}{l}\text { Session } \\
\text { No. }\end{array}$} & \multicolumn{5}{|c|}{ ACT Items } & \multirow{2}{*}{$\begin{array}{c}\text { Other Items } \\
\text { General Assessment }\end{array}$} & \multicolumn{4}{|c|}{ Anti-ACT Items } & \multirow{2}{*}{\begin{tabular}{|c|}
$\begin{array}{c}\text { Global Rating of } \\
\text { Adherence }\end{array}$ \\
$\begin{array}{c}\text { Overall Competence of } \\
\text { Therapist }\end{array}$ \\
\end{tabular}} \\
\hline & & $\begin{array}{c}\text { Deliteralization } \\
\text { / Defusion }\end{array}$ & $\begin{array}{l}\text { Willingness } \\
\text { Acceptance }\end{array}$ & $\begin{array}{c}\text { Creative } \\
\text { hopelessness/ } \\
\text { Workability/ } \\
\text { Control is Problem }\end{array}$ & Values \& Goals & Committed Action & & Challenging Cognitions & $\begin{array}{c}\text { Experiential Avoidant } \\
\text { Change Strategies }\end{array}$ & $\begin{array}{c}\text { Cognitive Therapy } \\
\text { Rational }\end{array}$ & $\begin{array}{l}\text { Thoughts and Feelings } \\
\text { Cause Action }\end{array}$ & \\
\hline \multirow{15}{*}{ This Study } & $\# 1$ & -- & -- & -- & -- & -- & -- & -- & -- & -- & -- & -- \\
\hline & $\# 2$ & -- & -- & -- & -- & - & -- & -- & -- & -- & -- & - \\
\hline & $\# 3$ & -- & -- & -- & -- & -- & -- & -- & -- & -- & -- & - \\
\hline & \# 5 & -- & -- & -- & -- & -- & -- & -- & -- & -- & -- & - \\
\hline & \# 6 & 5 & 5 & 2 & 2 & 2 & 1 & 1 & 2 & 1 & 1 & 5 \\
\hline & \# 7 & 5 & 5 & 3 & 4 & 1 & 1 & 1 & 1 & 1 & 1 & 5 \\
\hline & \# 8 & -- & -- & -- & -- & -- & -- & -- & -- & -- & -- & - \\
\hline & $\# 9$ & 1 & 1 & 1 & 5 & 5 & 1 & 1 & 1 & 1 & 1 & 5 \\
\hline & \# 10 & 1 & 1 & 1 & 2 & 5 & 2 & 1 & 1 & 1 & 1 & 5 \\
\hline & \# 12 & 5 & 2 & 1 & 1 & 2 & 1 & 1 & 1 & 1 & 1 & 5 \\
\hline & \# 13 & 1 & 5 & 2 & 2 & 2 & 1 & 1 & 1 & 1 & 1 & 5 \\
\hline & $\# 14$ & 4 & 3 & 3 & 3 & 2 & 1 & 1 & 1 & 1 & 1 & 4 \\
\hline & \# 15 & 3 & 3 & 1 & 4 & 4 & 1 & 1 & 1 & 1 & 1 & 4 \\
\hline & Mean & 3.10 & 3.50 & 1.60 & 2.80 & 3.00 & 1.60 & 1.00 & 1.10 & 1.00 & 1.00 & 4.80 \\
\hline & SD & 1.81 & 1.63 & 0.80 & 1.33 & 1.48 & 1.20 & 0.00 & 0.30 & 0.00 & 0.00 & 0.40 \\
\hline \multirow{2}{*}{$\begin{array}{l}\text { Towing et } \\
\text { al. }\end{array}$} & Mean & 2.50 & 2.80 & 3.30 & 2.40 & 1.80 & 3.10 & -- & -- & -- & -- & 4.40 \\
\hline & SD & 1.30 & 1.20 & 1.70 & 1.70 & 0.90 & 0.80 & -- & -- & -- & -- & 0.50 \\
\hline
\end{tabular}


Table 2. Scores On Process and Outcome Measures at Four Time Points and Their Reliable Change Indexes (RCI)

\begin{tabular}{|c|c|c|c|c|c|c|c|c|c|c|}
\hline \multirow{2}{*}{ Measure } & \multirow{2}{*}{ SD } & \multirow{2}{*}{ Sdiff } & \multirow{2}{*}{$\alpha$} & \multicolumn{4}{|c|}{ Scores } & \multicolumn{3}{|c|}{ RCI } \\
\hline & & & & T1 & $\mathrm{T} 2$ & $\mathrm{~T} 3$ & $\mathrm{~T} 4$ & $\mathrm{~T} 2-\mathrm{T} 1$ & T3 - T1 & $\mathrm{T} 4$ - T1 \\
\hline BDI-II & 6.84 & 2.16 & 0.95 & 21 & 4 & 4 & 14 & 7.86 & 7.86 & 3.24 \\
\hline GHQ-30 & 2.65 & 1.19 & 0.90 & 14 & 0 & 0 & 17 & 11.81 & 11.81 & -2.53 \\
\hline STAI-T & 9.20 & 4.11 & 0.90 & 65 & 48 & 41 & 55 & 4.13 & 5.83 & 2.43 \\
\hline STAI-S & 8.80 & 4.13 & 0.89 & 56 & 45 & 45 & 54 & 2.67 & 2.67 & 0.48 \\
\hline AAQ-II & 8.10 & 3.97 & 0.88 & 28 & 24 & 18 & 24 & 1.01 & 2.52 & 1.01 \\
\hline FFMQ & 13.03 & 8.24 & 0.80 & 96 & 129 & 135 & 117 & 4.00 & 4.73 & 2.55 \\
\hline CFQ-28 & 20.14 & 9.87 & 0.88 & 141 & 101 & 91 & 114 & 4.05 & 5.07 & 2.74 \\
\hline
\end{tabular}

Notes on measures:

BDI-II = Beck Depression Inventory- Second Edition.

GHQ-30 = General Health Questionnaire-30 items.

STAI-T = State Trait Anxiety Inventory-Trait.

STAI-S = State Trait Anxiety Inventory-State.

AAQ-II = Acceptance and Action Questionnaire-Second Edition.

FFMQ=Five Facts Mindfulness Questionnaire.

CFQ-28=Cognitive Fusion Questionnaire-28 items.

Notes on statistics:

Sdiff $=$ Standard error of difference.

$\alpha=$ Cronbach's alpha.

$\mathrm{T} 1=$ scores at pretreatment.

$\mathrm{T} 2=$ scores at post-treatment (12 Sessions).

$\mathrm{T} 3=$ scores at the third booster session (15 Sessions in total).

$\mathrm{T} 4=$ scores at the fourth follow-up (19 sessions in total).

$\mathrm{T} 2-\mathrm{T} 1=\mathrm{RCI}$ for pre-post treatment difference.

$\mathrm{T} 3-\mathrm{T} 1=$ pre-treatment - third booster session difference.

$\mathrm{T} 4-\mathrm{T} 1=$ pre-treatment - follow-up 4 difference.

RCI=Reliable Change Index, which was calculated according to the formula given by Jacobson \& Truax (1991). The RCI value $\geq 1.96$ is statistically significant. 
with Chronic Depression: A Replicated Treatment-Evaluation

T. Muto \& T. Mitamura

Pragmatic Case Studies in Psychotherapy, http://pcsp.libraries.rutgers.edu

Volume 11, Module 2, Article 2, pp. 117-153, 06-12-15 [copyright by authors]
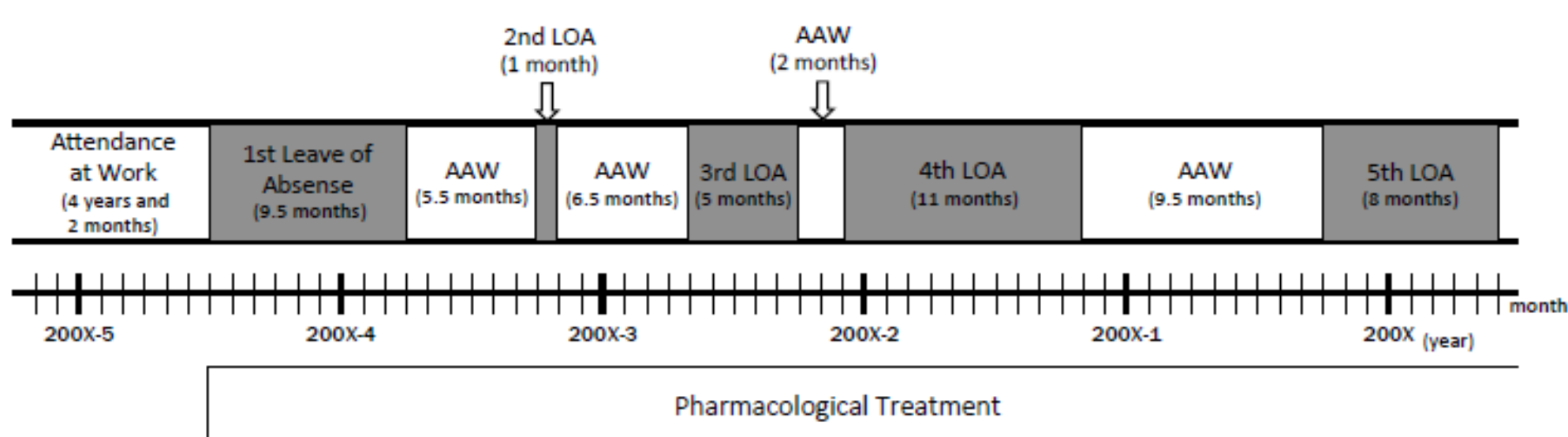

Rehabilitatio

Program

ACT

Figure 1. Timeline of the Client's Leave of Absence From Work (Attendance at Work) and Implemented Treatments 


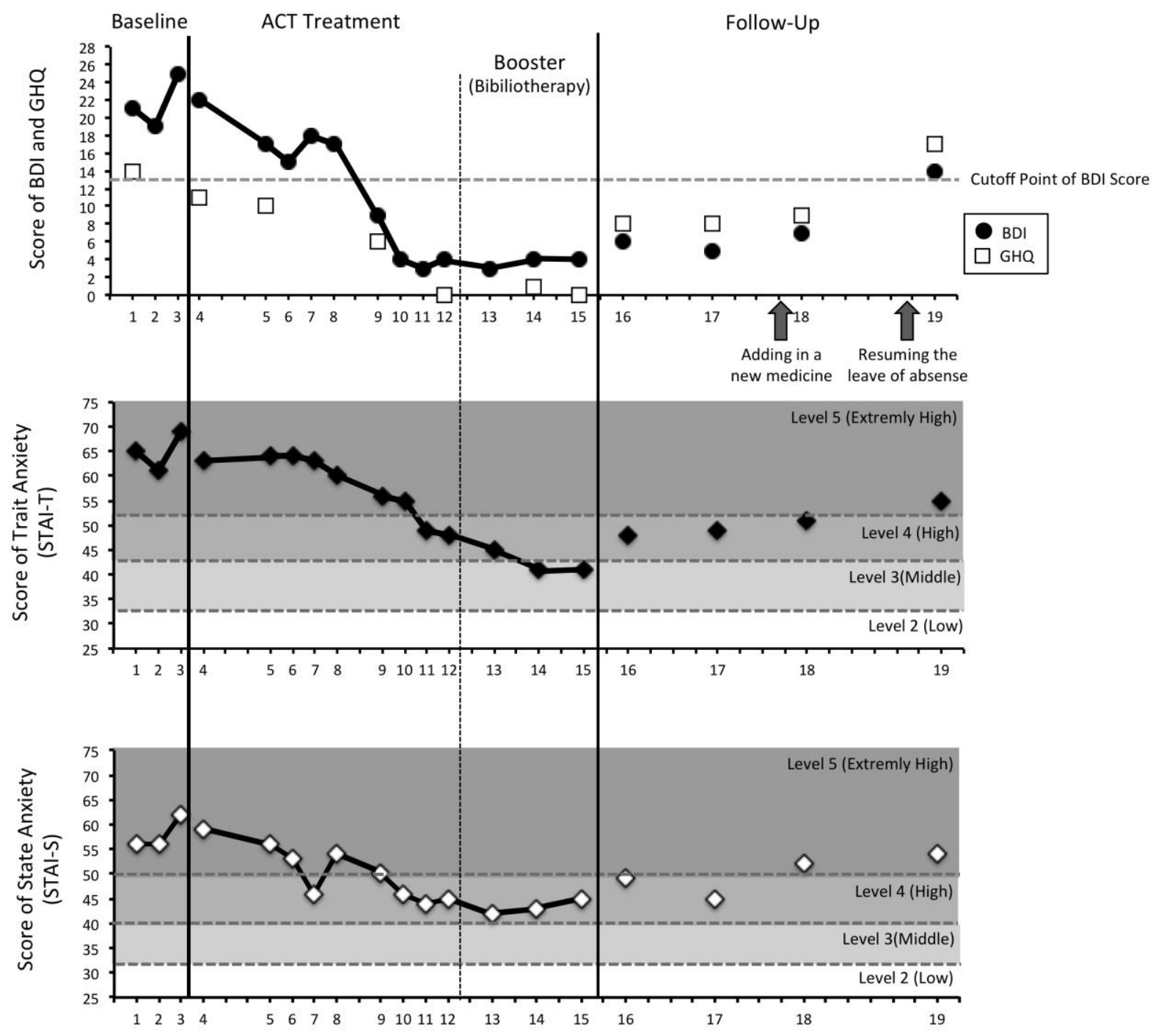

Figure 2. Scores of Outcome Measures (BDI-II, GHQ 30, and STAI) in Baseline, Act Treatment, and Follow-Up Phases

Note: The upper figure describes scores of the BDI-II and the GHQ 30; the middle figure describes scores of the STAI-Trait; and the lower figure describes scores of the STAI-State. 


\section{T. Muto \& T. Mitamura}

Pragmatic Case Studies in Psychotherapy, http://pcsp.libraries.rutgers.edu

Volume 11, Module 2, Article 2, pp. 117-153, 06-12-15 [copyright by authors]
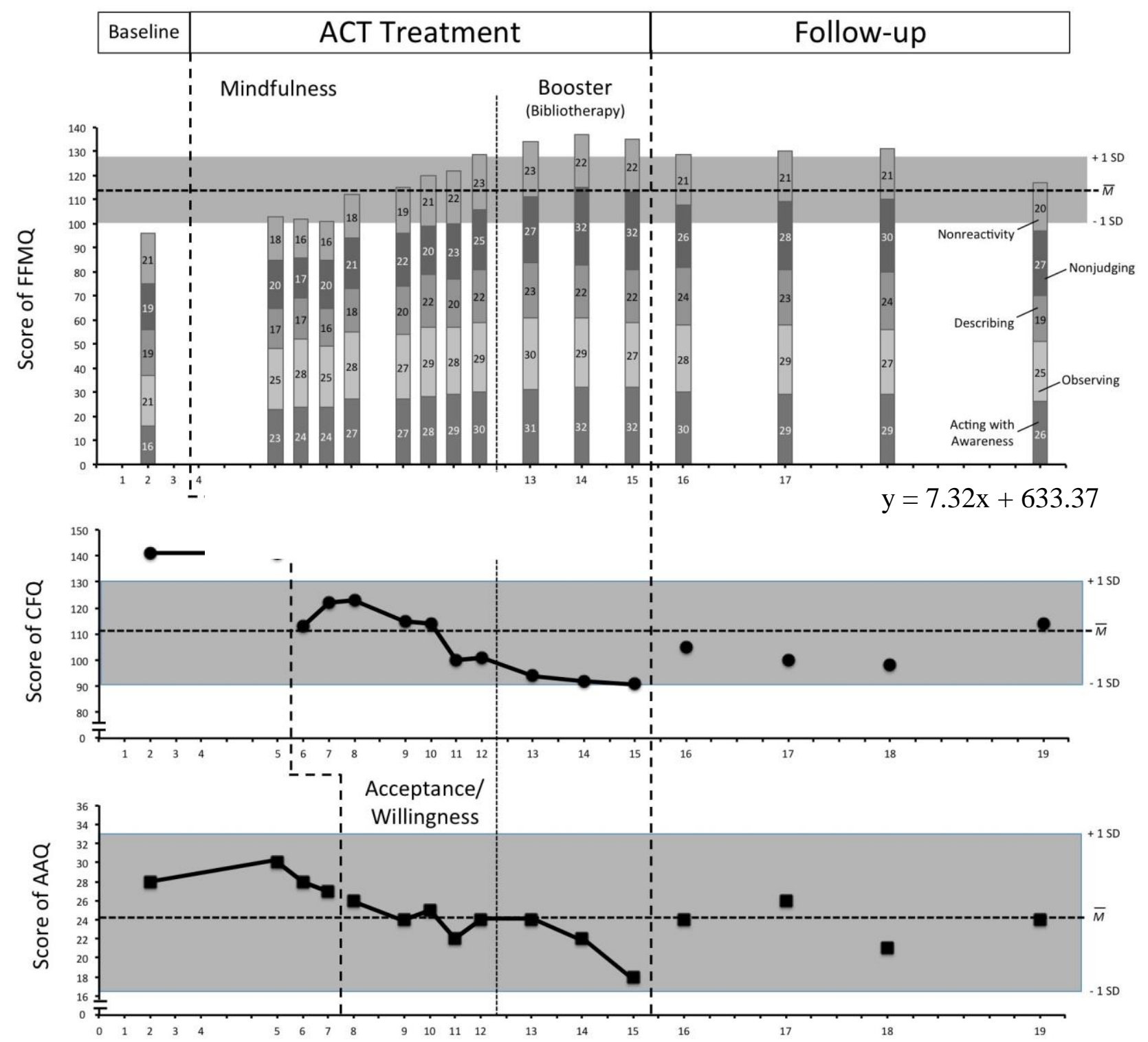

Weeks with Seesion Number

Figure 3. The Scores of Outcome Measures (FFMQ, CFQ-28, and AAQ-II) in Baseline, Act Treatment, and Follow-Up Phases

Note: The upper figure describes scores of the FFMQ (in order from the bottom of each bar, the score of Acting with Awareness, Observing, Describing, Non-Judging, and Non-Reactivity); the middle describes scores of the CFQ--28; and the lower describes scores of the of AAQ---II. 


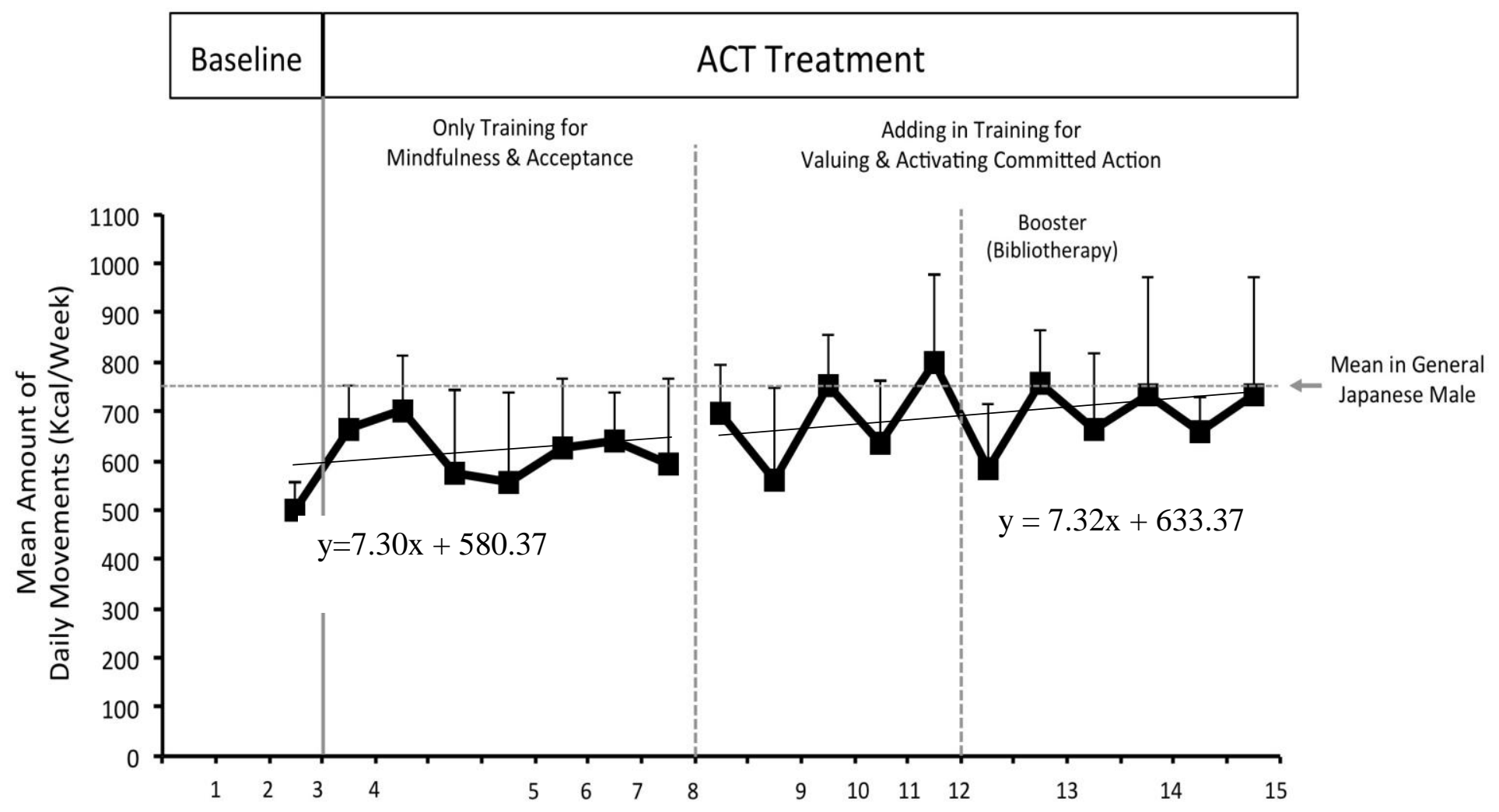

Weeks with Session Number

Figure 4. The Mean Amount of Daily Movement (An Outcome Measure for "Commitment Side" of ACT) in Baseline and in Treatment.

Note: The error bar describes the standard error of the mean.

The solid line within the graph describes the regression line within the data for the treatment's three phases: baseline, "only training for mindfulness and acceptance," and "adding training for valuing and activating committed action."

The regression lines were mathematically calculated.

The dotted line describes the mean amount of daily movements in the general Japanese male population. 


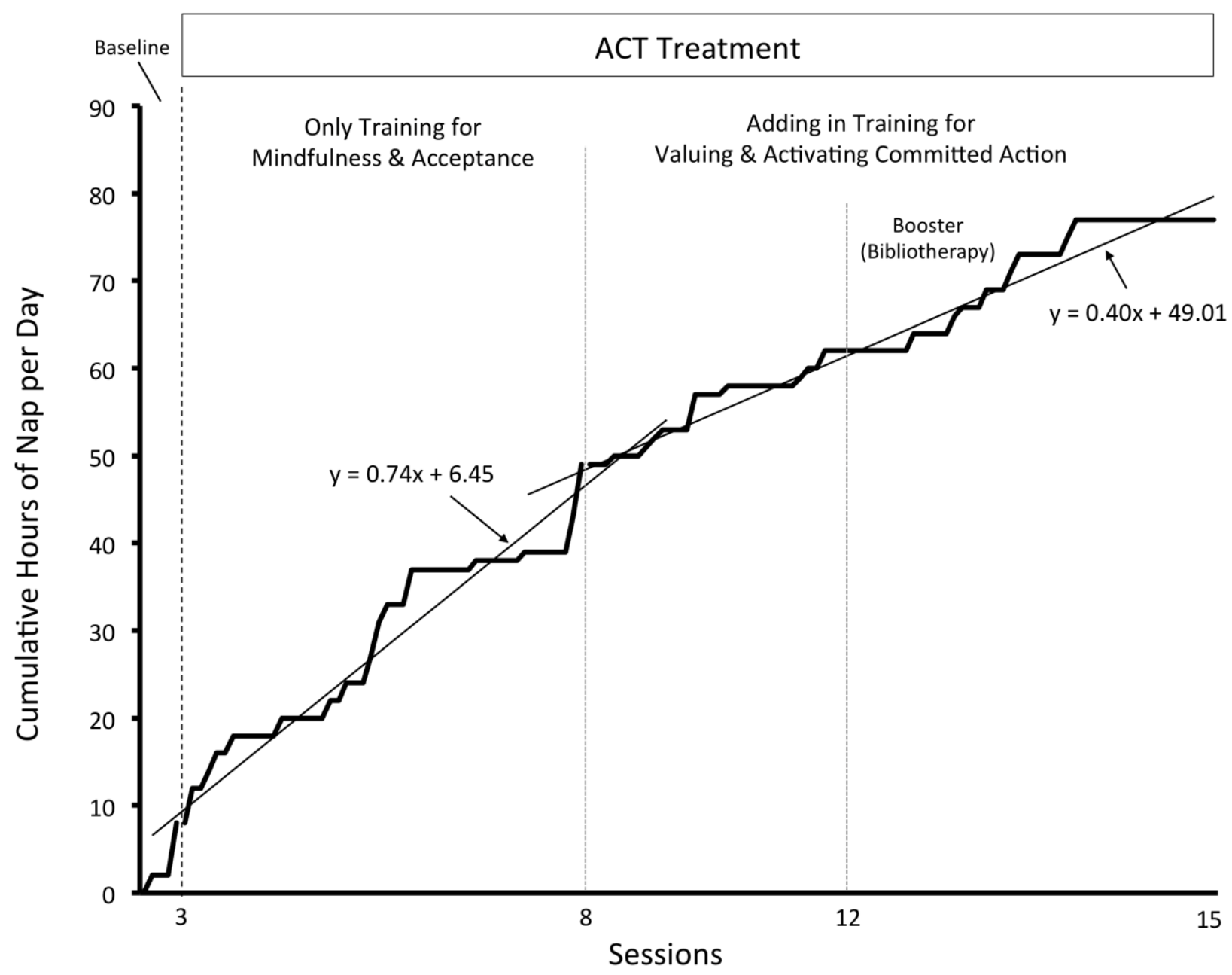

Figure 5. The Cumulative Hours of Naps Per Day

(An Outcome Measure for the "Commitment Side" of ACT).

Note: The two solid lines within the graph describe the regression line of data in baseline and in the two treatment phases, "only training for mindfulness and acceptance" and "adding training for valuing and activating committed action." The regression lines were mathematically calculated. 